\title{
Optimal Design of Cash Circulation Module Gear for Financial Machinery Based on Tribology
}

\author{
Weisong Yang, ${ }^{1,2}$ Shukun Wang $\mathbb{D}^{1},{ }^{1}$ Wei Song, ${ }^{2}$ and Lili Ren ${ }^{3}$ \\ ${ }^{1}$ College of Mechanical and Electric Engineering, Changchun University of Science and Technology, Changchun 130022, China \\ ${ }^{2}$ Eastern Communications Co., Ltd., Hangzhou 310053, China \\ ${ }^{3}$ Key Laboratory of Bionic Engineering (Ministry of Education), College of Biological and Agricultural Engineering, \\ Jilin University, Changchun 130022, China \\ Correspondence should be addressed to Shukun Wang; wsk@cust.edu.cn
}

Received 11 July 2019; Revised 24 September 2019; Accepted 8 October 2019; Published 28 April 2020

Academic Editor: Francesco Aggogeri

Copyright (c) 2020 Weisong Yang et al. This is an open access article distributed under the Creative Commons Attribution License, which permits unrestricted use, distribution, and reproduction in any medium, provided the original work is properly cited.

\begin{abstract}
To achieve the characteristics of the cash cycle module of a financial machine, such as a compact transmission mechanism, high transmission accuracy, large torque, high rotation speed, high service temperature, no lubrication, and long service life, this work presented a solution to optimize the tooth shape of a thermoplastic gear and the design of a thermoplastic gear with a limit pressure angle of $35^{\circ}$. Through the modeling and simulation analysis of the factors affecting the life of the gear, it was found that the gear with the improved tooth profile was superior to the control gear without the improved tooth profile in terms of sliding wear of the tooth surface, thermal deformation wear, and interference wear. The experimental results demonstrated that the wear resistance of a thermoplastic gear with a tooth profile of $35^{\circ}$ was 1.1 times higher than that of the gear with a tooth profile of $20^{\circ}$, which was consistent with the simulation analysis results and can be used as a theoretical basis for thermoplastic gear design in related fields.
\end{abstract}

\section{Introduction}

A cash circulation module is used for the deposit, transmission, and identification of banknotes in financial instruments, and its transmission system is composed primarily of gears. A cash circulation module has more than 300 gears in its transmission system. A cash circulation module is usually placed in a safe because it involves cash, which means that the cash circulation module operates in an unlubricated environment with a narrow space and high temperature. However, metal gears do not satisfy requirements such as high speed of money receipt and low noise. Compared with metal gears, thermoplastic gears have the characteristics of less weight, low noise, stainlessness, and the ability to work under no lubrication conditions, which can meet the requirements for cash circulation modules of financial instruments. However, plastic is a viscoelastic material, and its failure form and mechanism are quite different from those of metal gears; in open transmission, gear tooth wear is the main failure form of plastic gears [1].
Therefore, the reduction of gear wear and improvement in the life of thermoplastic gears have become popular research topics. In $[2,3]$, the authors proposed a method to improve the service life of a plastic gear by enhancing the thermal conductivity of materials by using calculation and analysis methods. Franklin [4] performed conducting wear tests under dry reciprocating sliding conditions and reported that the reduction of friction heat and improvement of wear resistance could be realized by reducing the friction coefficient of materials. Yousef et al. concluded that the use of suitable materials could reduce the friction and improve the fatigue strength and wear resistance of gears [5-8] and that better performance could be achieved by introducing certain modifications [9-11]. Taburdagitan and Akkok [12] analyzed the friction heating process of a cylindrical spur gear and calculated the instantaneous temperature rise of a tooth surface using the finite element method. The Blok flash temperature formula was used to theoretically verify the simulation results for the tooth surface flash temperature, and the distribution law of the temperature rise of the tooth 
surface in the meshing process was comprehensively analyzed. It was concluded that the sliding rate and contact strength exerted direct influence on the temperature rise of the tooth surface. Mao [13] extensively analyzed the instantaneous temperature rise and heat flow distribution of the tooth surface of a plastic helical gear in the meshing process and numerically calculated the average instantaneous temperature of the tooth surface in the meshing area in combination with the finite element method. Kapelevich [14] proposed the design idea of a larger pressure angle on the working face and smaller pressure angle on the nonworking face of the asymmetric gear with one-way operation and pointed out that the gear has the characteristics of large tooth root bending strength, small volume, low vibration, and noise. The abovementioned studies analyzed the main factors affecting the gear life, involved considerable efforts to improve the material, and clarified that the modification of materials could help improve the gear life. However, improvement in the gear life through the modification of the symmetry tooth profile has not been reported yet.

Considering the two-way working characteristics of the cash circulation module of financial machinery, this paper proposes a solution to optimize the tooth profile of thermoplastic gear, discusses the design of a thermoplastic gear with a maximum symmetry pressure angle of $35^{\circ}$, and clarifies the influence of the improvement of the tooth profile on the life of the gear by comparing it with an existing gear with a symmetry pressure angle of $20^{\circ}$.

\section{Materials and Methods}

2.1. Materials. Polyformaldehyde of the RTP0800 type (RTP0800-POM) was purchased from RTP company. According to ASTM D-3702, (US), the specific performance parameters of RTP0800-POM were obtained by performing a thrust washer wear test using the ECT1604 equipment, as given in Table 1.

2.2. Calculation of Gear Pressure Angle. According to the addendum thickness formula of the tooth tip of the symmetric gear, the pressure angle of the gear is calculated by the following formula:

$$
\begin{aligned}
S_{\mathrm{e}} & =d_{\alpha}\left[\frac{1}{2 \pi}(\pi+4 \times x \tan \alpha)+i n v \alpha-i n v \alpha_{\alpha}\right], \\
\cos \alpha_{\alpha} & =\frac{d \cos \alpha}{d_{\alpha}} \\
i n v \alpha & =\tan \alpha-\frac{2 \pi}{360} \alpha,
\end{aligned}
$$

where $S_{\mathrm{e}}$ is the addendum thickness, $d_{\alpha}$ is the addendum circle diameter, $x$ is the displacement coefficient, $\alpha_{\alpha}$ is the addendum circle pressure angle, $\alpha$ is the indexing circle pressure angle, and $d$ is the indexing circle diameter.

The pressure angle of the gear was calculated by setting the coefficient $x$ of the gear. For the standard symmetric gear, when $x=0$, formulas (1)-(3) can be obtained that the maximum pressure angle of the gear is $35^{\circ}$ when the addendum thickness meets $S_{\mathrm{e}}>0$. Therefore, this paper chooses the standard symmetric gear with a pressure angle of $35^{\circ}$ and $20^{\circ}$ for comparative analysis.

The gear material was polyformaldehyde containing $2 \%$ silicone oil. The relevant parameters of gears with pressure angles $20^{\circ}$ and $35^{\circ}$ are listed in Table 2.

2.3. Statistical Analysis. All experimental data in this paper are expressed as the mean \pm standard deviation. The difference between the factors and levels was evaluated by the analysis of variance (ANOVA). Duncan's multiple range tests were used to compare the means to identify the groups that were significantly different from other groups. The statistical significance was set at $P<0.05$.

\section{Results and Discussion}

3.1. Kinematic and Dynamic Analyses of Gears. The wear amount of engineering plastics is usually determined using the following formula:

$$
W=K \times p \times v \times t
$$

where $W$ is the volume wear $\left(\mathrm{mm}^{3}\right), \mathrm{K}$ is the wear factor $\left(\mathrm{mm}^{3} / \mathrm{N} \cdot \mathrm{m}\right) \cdot 10^{-8}, p$ is the pressure $(\mathrm{MPa}), v$ is the velocity $(\mathrm{m} / \mathrm{sec})$, and $t$ is the elapsed time $(\mathrm{sec})$.

The wear of engineering plastics includes both adhesive wear and abrasive wear. Therefore, the influence of contact stress, relative sliding speed, and friction heat flow must be considered when establishing a mathematical model and using the MATLAB software to analyze the wear of a plastic gear mesh.

3.2. Effect of Pressure Angle on Contact Stress in the Gear Meshing Zone. According to the analysis of geometric relations between the surfaces of contact objects based on the Hertz theory, points with the same distance between the surfaces of objects form a region similar to an ellipse on the common section $[12,15]$ and the average contact pressure of the tooth surfaces can be calculated according to the following formula of the Hertz theory:

$$
P_{\mathrm{a}}=\frac{\pi}{4} \sqrt{\frac{F_{\mathrm{NC}} E}{2 \pi \rho_{\mathrm{ec}} b\left(1-V^{2}\right)}},
$$

where $P_{\mathrm{a}}$ is the average contact pressure of the tooth surfaces, $F_{\mathrm{NC}}$ is the normal load acting on the tooth surface, $E$ is the elastic modulus of gear material, $b$ is the gear width, $V$ is the gear material Poisson's ratio, and $\rho_{\mathrm{ec}}$ is the equivalent curvature radius of the meshing gear teeth and can calculated according to the following formula:

$$
\begin{aligned}
& \rho_{\mathrm{ec}}=\frac{\rho_{\mathrm{e} 1} \rho_{\mathrm{e} 2}}{\rho_{\mathrm{e} 1}+\rho_{\mathrm{e} 2}}, \\
& \rho_{\mathrm{e} 1}=\frac{1}{2} d_{1} \sin \alpha \pm g_{y M},
\end{aligned}
$$


TABLE 1: Wear test parameters.

\begin{tabular}{lcccccc}
\hline $\begin{array}{l}\text { RTP product } \\
\text { type }\end{array}$ & $\begin{array}{c}\text { Silicon oil } \\
\text { content }(\%)\end{array}$ & Loading $(\mathrm{lb})$ & Speed (ft/min) & PV (ft lb /in ${ }^{2}$ min) & $\begin{array}{c}\text { Wear factor } \\
\left(\mathrm{mm}^{3} / \mathrm{Nm}^{2} \mathrm{E}^{-8}\right.\end{array}$ & Friction coefficient \\
\hline RTP0800 & & 8 & 50 & 2000 & 187 & 0.4 \\
RTP0800 & 2 & 10 & 100 & 5000 & 206 & 0.42 \\
RTP0800 SI2 & 2 & 10 & 100 & 2000 & 55 & 0.43 \\
RTP0800 SI2 & 2 & 10000 & 92 & 0.41 \\
\hline
\end{tabular}

TABLE 2: Operating parameters of gears with different number of teeth.

\begin{tabular}{lcccccc}
\hline The gear teeth number & $\begin{array}{c}\text { Modulus } \\
(\mathrm{mm})\end{array}$ & $\begin{array}{c}\text { Driving wheel torque } \\
(\mathrm{mN} . \mathrm{m})\end{array}$ & $\begin{array}{c}\text { Speed } \\
(\mathrm{rpm})\end{array}$ & $\begin{array}{c}\text { Pressure } \\
\text { angle }\left({ }^{\circ}\right)\end{array}$ & $\begin{array}{c}\text { Tooth width } \\
(\mathrm{mm})\end{array}$ & $\begin{array}{c}\text { Modulus of elasticity } \\
(\mathrm{MPa})\end{array}$ \\
\hline 36 & 1 & 1000 & 750 & 35 & 6 & 27 \\
24 & 1 & 666 & 1125 & 35 & 7 & 2700 \\
35 & 1 & 1000 & 750 & 20 & 2700 & 2700 \\
22 & 1 & 666 & 1120 & 20 & 7 & 2700 \\
\hline
\end{tabular}

$$
\rho_{\mathrm{e} 2}=\frac{1}{2} d_{2} \sin \alpha \mp g_{y M},
$$

where $\rho_{\mathrm{e} 1}$ and $\rho_{\mathrm{e} 2}$ are the radius of curvatures of the tooth profile at the contact point of the gear tooth, $\mathrm{d} 1$ and $\mathrm{d} 2$ are the pitch circle diameters of the meshing gear, $\alpha$ is the pressure angle of the pitch circle, and $\mathrm{g}_{y M}$ is any contact point $M$ (as shown in Figure 1) on the tooth surface; the radius of this point on the driving wheel is $r_{M}$, which is the position on the gear engagement line, that is, the distance between the contact point $M$ (as shown in Figure 1) and the node on the engagement line:

$$
g_{y M}=\mp \frac{1}{2} d_{1} \sin \alpha \pm \sqrt{\left(\frac{1}{2} d_{1} \sin \alpha\right)^{2}-\left(\frac{1}{2} d_{1}\right)^{2}+r_{M}^{2}}
$$

In equation (6), the above set of symbols is applicable to the tooth root contact point of the driving wheel or driven wheel, while the following set of symbols is applicable to the tooth root contact point of the driving wheel or driven wheel. Formula (7) corresponds to the normal load acting on the tooth surface, and the coefficient of load distribution between the teeth in the gear meshing area is set as $\mathrm{K}$; thus, the normal load of the gear tooth profile can be expressed by the torque $T_{1}$ of the driven wheel shaft, as follows:

$$
F_{\mathrm{NC}}=\frac{K T_{1} z_{1} / z_{2}}{r_{M} \cos \alpha}
$$

The distribution of load between the teeth, generated by the alternate meshing of the gear teeth during work, and the influence of gear teeth biting and biting impact (as shown in Figure 2) make the contact pressure distribution of the gear tooth surface uneven.

Based on the abovementioned results, the average contact pressure in the gear meshing area was simulated and analyzed. The simulation analysis results of the pinion as the main driving wheel are shown in Figure 3. The coordinates from the left to right indicate the tooth root bite point, single tooth bite point, and tooth tip bite point of the double tooth

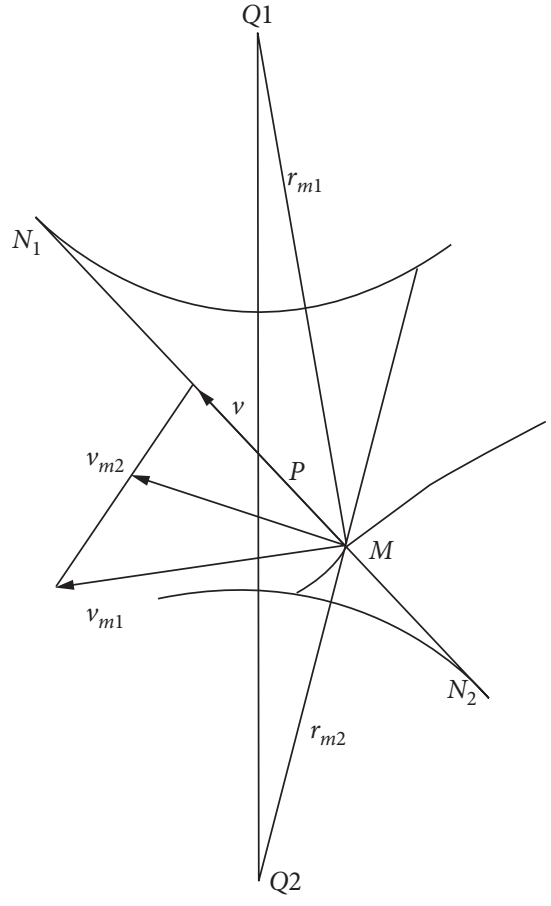

Figure 1: Meshing point velocity.

mesh active large gear, respectively. The average contact pressure in the mesh area for gear pressure angles of $20^{\circ}$ and $35^{\circ}$ was, respectively, represented as $P_{\mathrm{a}\left(20^{\circ}\right)}$ and $P_{\mathrm{a}\left(35^{\circ}\right)}$ in Figure 3 . The variation rule and distribution of the average contact pressure of the tooth surface from the root of the tooth to the top of the tooth could be obtained under different pressure angles. When the pressure angle was $20^{\circ}$, the average contact pressure of the tooth surface of the gear reached the maximum value of one meshing cycle in the meshing area of a single pair of teeth, that is, $68 \mathrm{MPa}$. When the pressure angle was $35^{\circ}$, the average contact pressure of the tooth surface of the gear, irrespective of whether single tooth or double tooth meshing area was considered, presented a significant downward trend, and the maximum average contact pressure of the tooth surface was $56 \mathrm{MPa}$. 


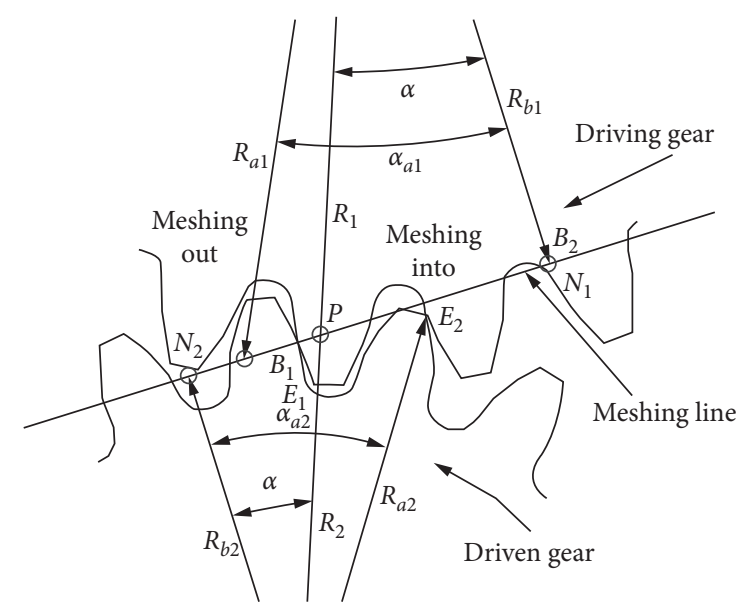

Figure 2: Gear mesh zone diagram.

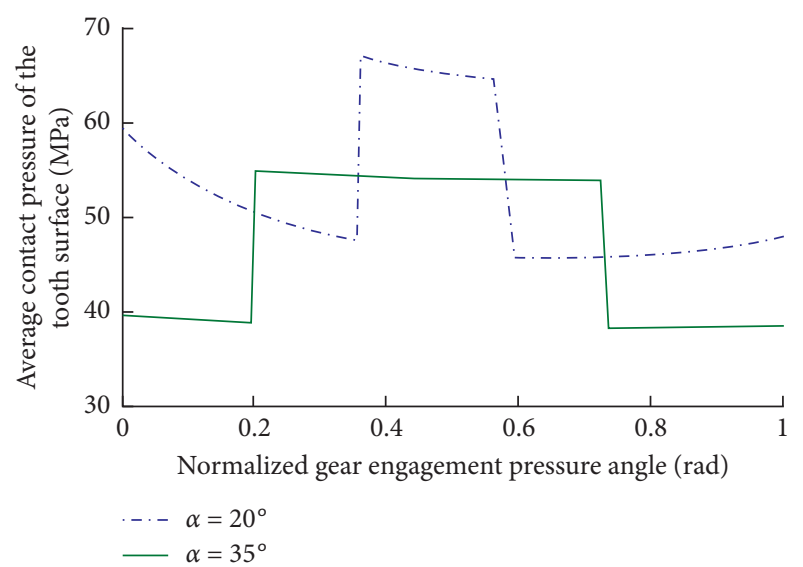

FIGURE 3: The simulation analysis results of pinion as the main driving wheel.

\subsection{Effect of Pressure Angle on the Relative Sliding Speed in the} Gear Mesh Area. The involute of the gear is formed by pure rolling of the generating line on the base circle; however, in the actual working meshing process, relative sliding occurs between the gear teeth. The relative sliding speed of gear teeth is different at different engagement points; the relative sliding speed near the nodal line is the minimum, and the

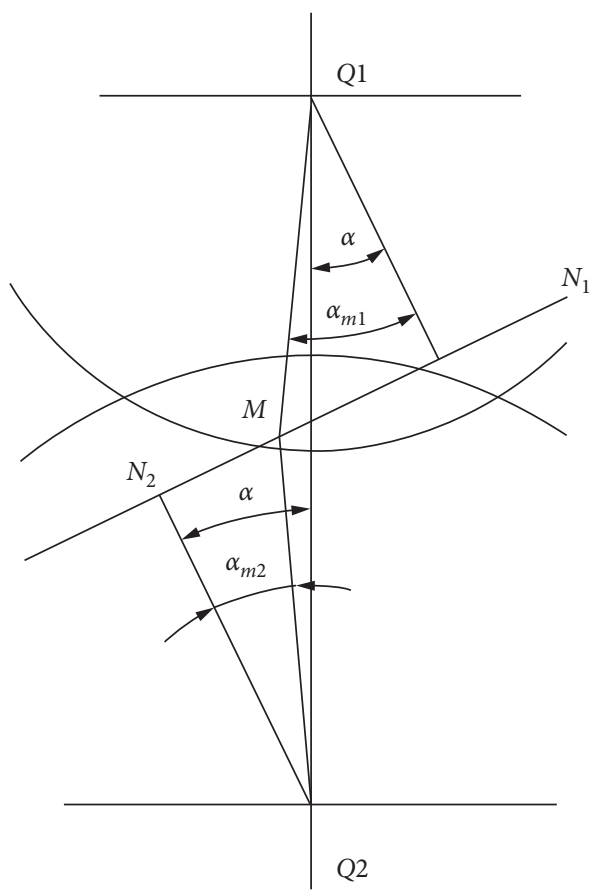

Figure 4: Meshing point pressure angle.

relative sliding speed at the nodal line is 0 [16]. Under the action of positive pressure between tooth profiles, tooth surface wear occurs due to relative sliding. Long-term experiments indicated that under certain conditions, the ratio of tooth surface wear of a pair of gears engaged at any point is equal to that of the tooth profile sliding coefficient $[17,18]$. Based on this finding, the degree of tooth surface wear is usually reflected by the sliding coefficient of the tooth profile. The relative sliding velocity of the gear profile at different points was obtained by analyzing the kinematics of the gear teeth. As shown in Figures 1 and 4, assuming the tooth surfaces of gears 1 and 2 engage at point $m$ at a certain moment, the expression of their relative sliding speed is given in equation (8) and the relative sliding rate is defined in equations (9) and (10).

According to Figures 1 and 4, the relative sliding velocity of $\mathrm{M}$ points can be obtained as follows:

$$
v_{m}^{21}=v_{m 1}-v_{m 2}=\omega_{m 1}\left[\left(1+\frac{1}{i_{21}} r_{m 1} \cos \alpha \tan \alpha_{m 1}-\frac{1}{i_{21}}\left(r_{1}+r_{2}\right) \sin \alpha\right)\right]
$$

where $v_{m}^{21}$ is the relative sliding speed of gears at different meshing points, $v_{m 1}$ and $v_{m 2}$ are the sliding speed of the driving and driven gears, $i_{21}$ is the ratio of the teeth of the driven and driving gears, $r_{m 1}$ is the driving gear meshing radius, $\alpha_{m 1}$ is the pressure angle of the meshing point of the driving gear, $r_{1}$ and $r_{2}$ are the radius of the gear indexing circle, and $\alpha$ is the pressure angle of the gear indexing circle. 
The relative slip rate of the driving and driven gears is

$$
\begin{aligned}
& \lambda_{1}=\frac{v_{m}^{21}}{v_{m 1}}=\left(1+\frac{1}{i_{21}}\right)\left[\begin{array}{ll}
\cos \alpha & \tan \alpha_{m 1}-\sin \alpha
\end{array}\right], \\
& \lambda_{2}=\frac{v_{m}^{21}}{v_{m 2}}=\left(1+i_{21}\right)\left[\begin{array}{ll}
\cos \alpha & \tan \alpha_{m 1}-\sin \alpha
\end{array}\right] .
\end{aligned}
$$

According to equations (9) and (10), a gear with a modulus of 1 , number of driving wheel teeth of 36 , number of driven gear teeth of 24 , and indexing circle pressure angles of $20^{\circ}$ and $35^{\circ}$ was used for simulation, as shown in Figures 5 and 6. It can be seen from the figures that the absolute value of relative sliding speed of the gear at the node position is 0 and gradually increases towards the gear tooth top and the tooth root meshing area; when the pressure angle of the indexing circle increases from $20^{\circ}$ to $35^{\circ}$, the absolute value of relative sliding speed at each meshing point decreases. It can be concluded that the absolute value of relative sliding speed of gear decreases when the pressure angle of indexing circle increases.

3.4. Effect of Pressure Angle on the Friction Heat Flux in the Gear Mesh Area. For a plastic gear, the failure mode changes with the difference in the material properties. Compared with a metal gear, a plastic gear has poor thermal conductivity, poor heat resistance, and low thermal expansion factor, and it is easily affected by temperature. Yousef et al. [5] considered a plastic spur gear as the research object and proposed a method to predict the meshing temperature and fatigue strength of spur gear transmission considering plastic thermoplasticity.

The frictional heat flux $q_{c 1}$ and $q_{c 2}$ of the main and driven wheels at contact point $\mathrm{C}$ of the teeth at any meshing position can be, respectively, expressed as

$$
\left\{\begin{array}{l}
q_{c 1}=\beta_{1} q_{c}=\beta_{1} \eta \mu_{c} P_{\mathrm{nc}} V_{\mathrm{gc}} \times 10^{6}, \\
q_{c 2}=\beta_{2} q_{c}=\beta_{2} \eta \mu_{c} P_{\mathrm{nc}} V_{\mathrm{gc}} \times 10^{6},
\end{array}\right.
$$

where $\beta_{1}$ and $\beta_{2}$ are the distribution factors of the friction heat flux density and $\beta_{1}+\beta_{2}=1, \eta$ is the coefficient on the conversion of friction energy to heat energy, $\mu_{c}$ is the friction factor, $P_{\mathrm{nc}}$ is the tooth surface contact pressure, and $V_{\mathrm{gc}}$ is the relative sliding speed of the tooth surface. Assuming that the frictional heat flux $q_{c}$ of the driving wheel and driven wheel are equally distributed, then $\beta_{1}=\beta_{2}=0.5$.

Gear 1 had the following specifications: the modulus was 1 , tooth number was 36 , material was POM, and biting was from the root to the top of the tooth. Gear 2 had the following specifications: the modulus was 1 , tooth number was 24 , and material was POM. Since the two materials used for the preparation of the gear were the same, the heat distribution coefficient beta was $\beta_{1}=\beta_{2}=0.5$. The heat flux of the gear in the meshing area is shown in Figure 7 .

Figure 7 indicates that the frictional heat flow density of the gear is zero at the pitch circle and increases towards the tooth root and the tooth top meshing area, the frictional heat flux density in the gear root meshing area is higher than that in the gear tip meshing area, the frictional heat flow density

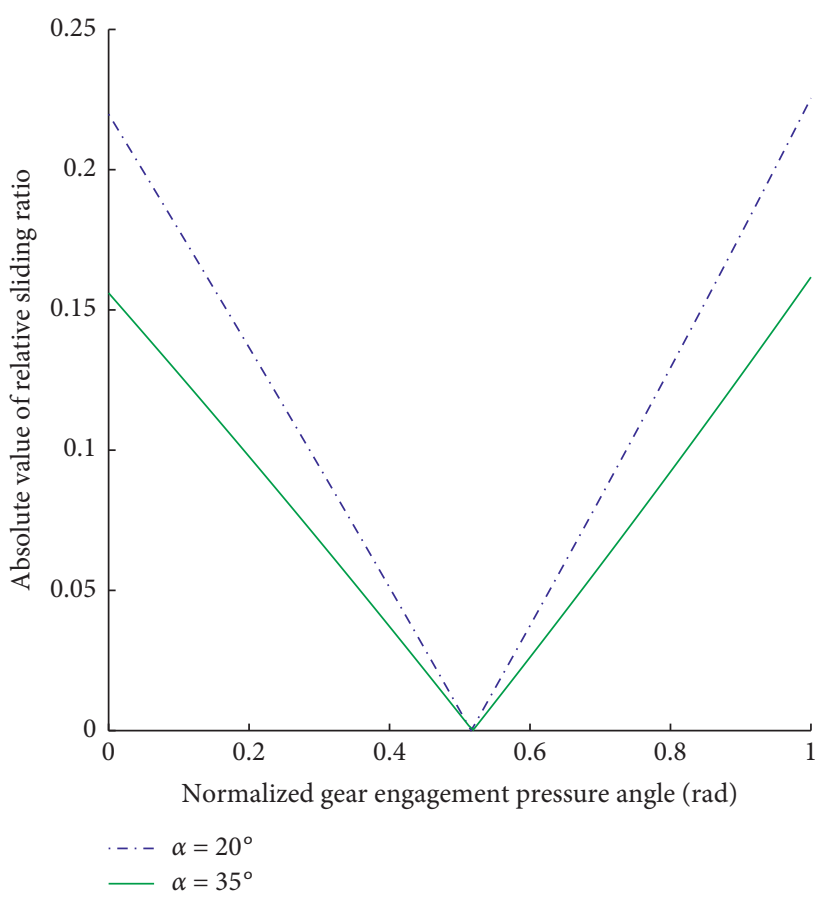

FIgURE 5: Absolute value of relative sliding ratio of the small gear.

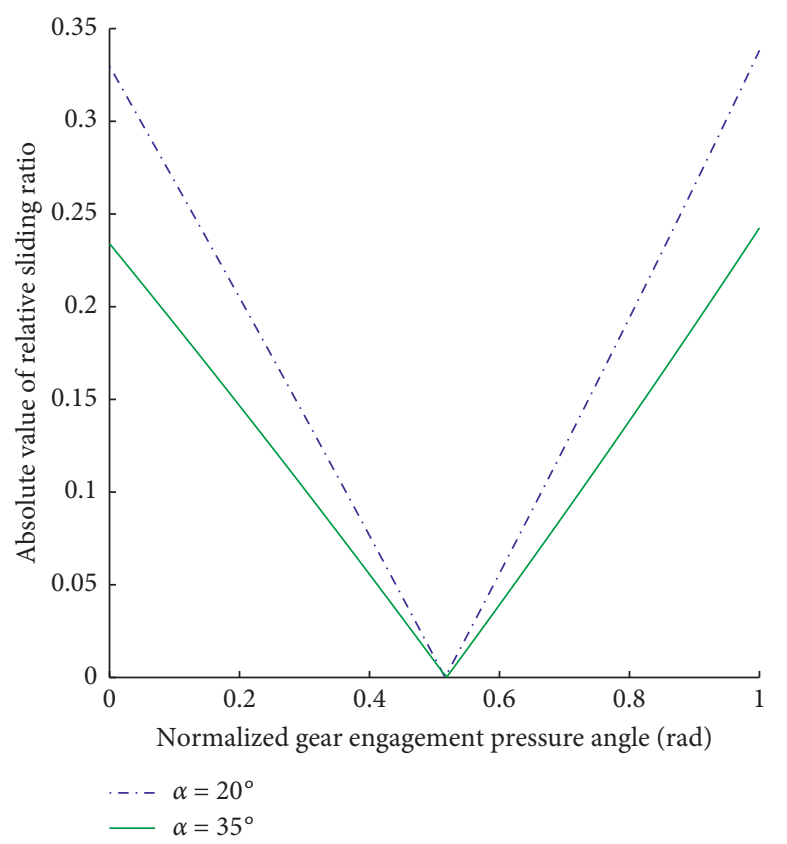

FIgURE 6: Absolute value of relative sliding ratio of the big gear.

of the gear tooth at each point in the meshing area decreased with the increase in the indexing circle pressure angle, and the amplitude of frictional heat flow at the tooth root and tooth part decreases more obviously. Therefore, increasing the indexing circle pressure angle was beneficial in reducing the friction heating of the tooth surface.

\subsection{Effect of Pressure Angle on Tooth Profile Interference Wear.} For involute gear transmission, the working tooth profile curves of the large and small gears are both involute. When 


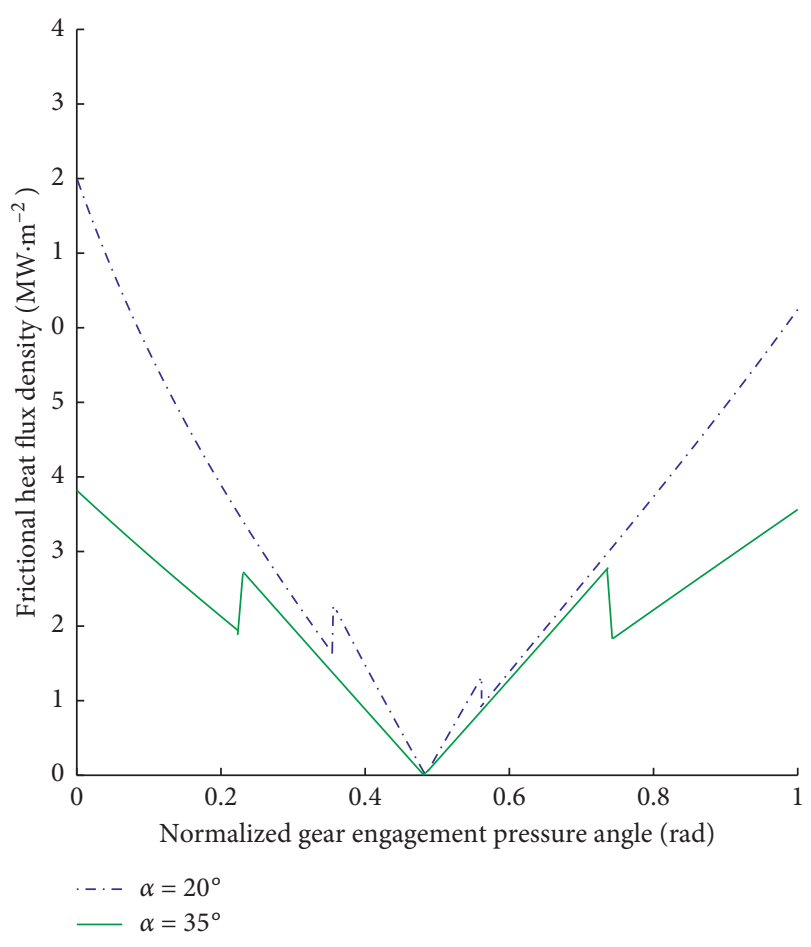

Figure 7: The heat flux of the gear in the meshing area.

the gear teeth number is small, the base circle is larger than the root circle, and thus, the tooth profile curve from the base circle to the root circle is noninvolute. The tooth surface of the involute part of the top of the large gear and the noninvolute tooth surface of the root part of the small gear contact is the tooth profile interference [19]. Thus, the interference of gears depends on the difference between the diameters of the bottom circle of teeth and the base circle, and this difference is related to the number of teeth and pressure angle, as shown in Figure 8. For gears with modulus 1 , when the pressure angle of the indexing circle is $20^{\circ}$, the root circle diameter of the gear with 15 teeth is less than the base circle diameter. When the pressure angle of the indexing circle is $35^{\circ}$, the root circle diameter of the gear with 15 teeth is larger than the base circle diameter.

If the gear base circle is larger than the tooth root circle, the tooth profile curve from the base circle to the tooth root circle is noninvolute, so it is necessary to modify the tooth profile curve during gear processing. The main processing mode of plastic gears is injection molding. During injection molding, the volume shrinkage of each point on the gear is different, as shown in Figure 9. Therefore, it is difficult to avoid tooth profile interference and wear by modifying the tooth profile curve.

It can be concluded that when the number of teeth is small, the larger the pressure angle of the dividing circle is, the more favorable it is to prevent the tooth profile of the plastic gear from interfering wear.

3.6. Gear Processing. According to the calculation and analysis results for the gear, the software ProE was used to

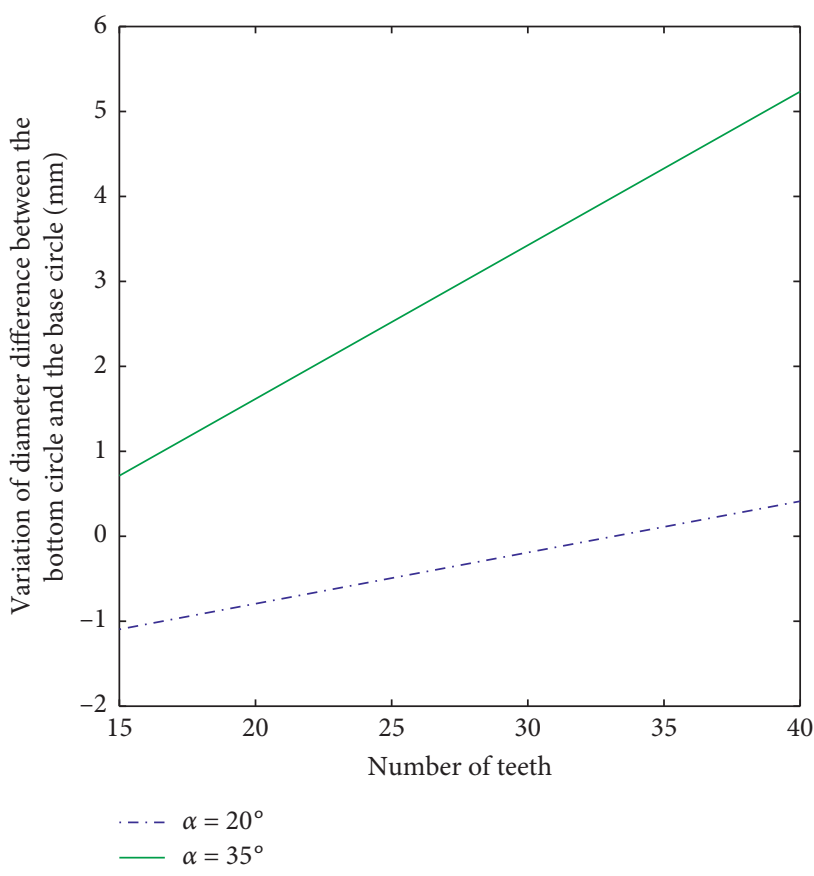

FIGURE 8: Variation of diameter difference between the bottom circle and the base circle with the number of teeth.

generate a $3 \mathrm{D}$ model and a gear manufacturing enterprise was entrusted to complete the injection molding of the gear. The gear was processed and molded using a mold, as shown in Figure 10. The gear materials and injection molding process are summarized in Table 3.

According to the requirements given in Table 2, a pair of $35^{\circ}$ pressure angle gears with 36 teeth and 24 teeth and a pair of $20^{\circ}$ pressure angle gears with 35 teeth and 22 teeth were processed. The self-developed TCRMe1000 large circulation module test machine was used for physical testing, and the prototype is shown in Figure 11.

Two pairs of plastic involute cylindrical gears with pressure angles of $20^{\circ}$ and $35^{\circ}$, made using POM, were installed in the transmission system of the test prototype for testing. The stress condition of each pair of gears was equivalent. After the pressure test, the influence of the pressure angle on the wear performance of gears was examined.

After the gear had operated for $3529 \mathrm{~h}$ on the test machine (shown in Figure 12), the images of the gears with different pressure angles, before and after wear, are shown in Figures 13 and 14.

Figures 13 and 14 indicate that compared with the tooth of the plastic gear with a pressure angle of $35^{\circ}$, the gear with a pressure angle of $20^{\circ}$ exhibited more critical tooth profile wear after pressure testing for $3925 \mathrm{~h}$, and notable burrs and black wear marks could be observed at the tooth root and tooth tip. The wear rates of the gears with different pressure angles in each stage are listed in Table 4.

Table 4 indicates that the wear rate of the gear increased with an increase in the test time; however, the wear rate of the gear with a pressure angle of $35^{\circ}$ exhibited a smaller increase with an increase in the test time. When the test time 


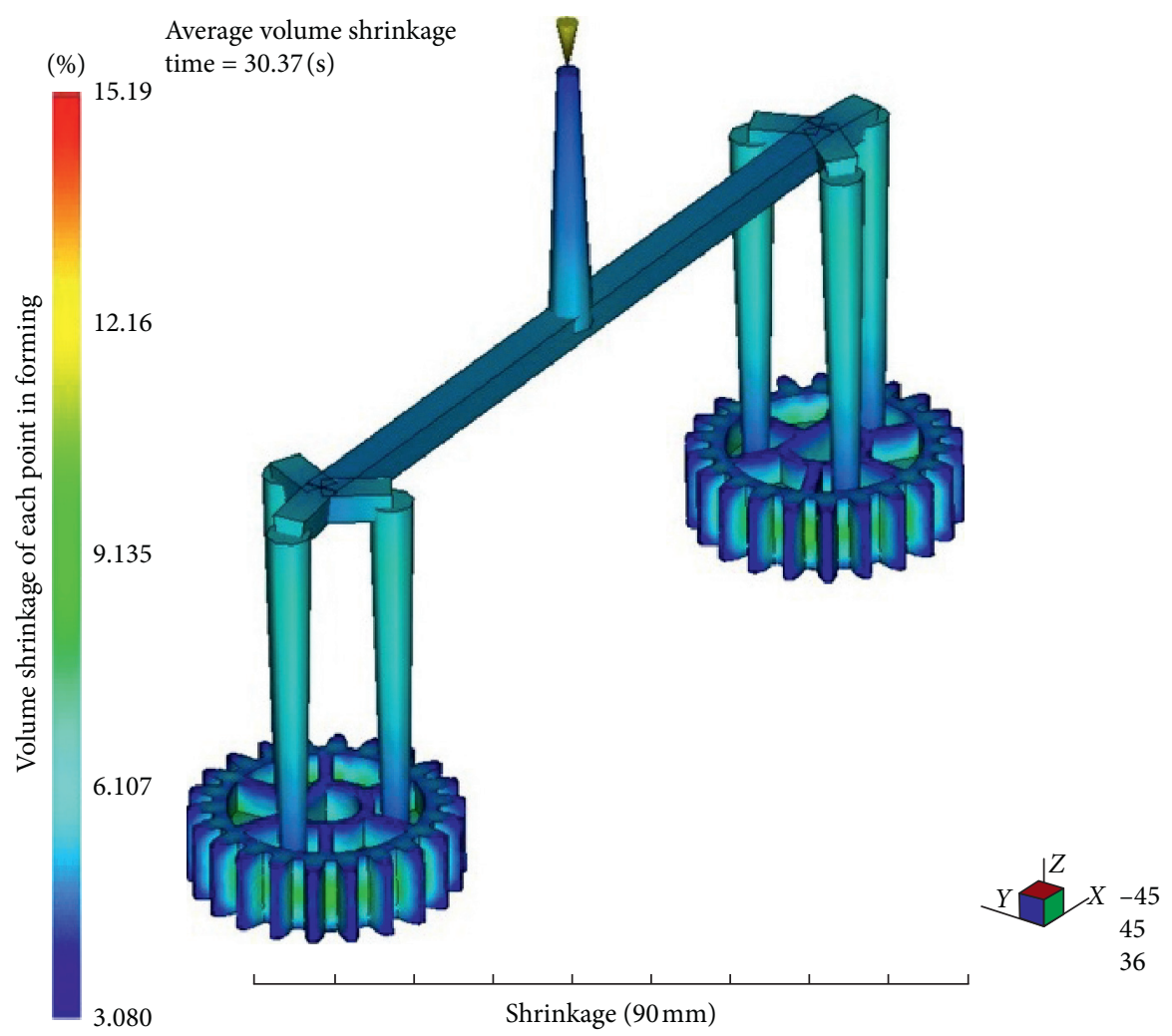

FIGURE 9: Volume shrinkage of plastic gears in forming.

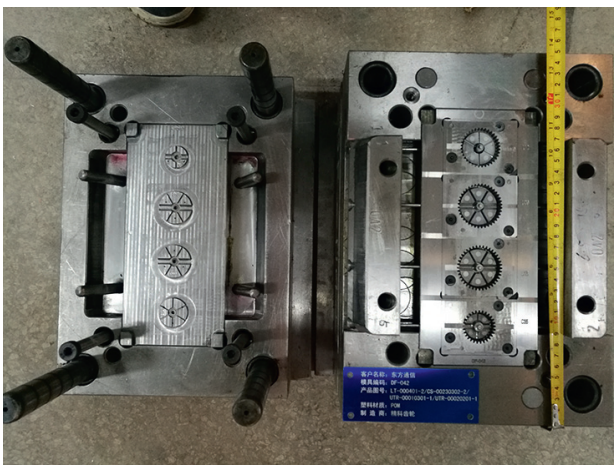

Figure 10: Photographs of the gear die.

TABLE 3: Gear forming parameters.

\begin{tabular}{lcccc}
\hline Equipment & Material & Molding cycle $(\mathrm{s})$ & Injection temperature $\left({ }^{\circ} \mathrm{C}\right)$ & Injection pressure $(\mathrm{MPa})$ \\
\hline Haitian120 T & RTP0800 & 33 & 225 & 77 \\
\hline
\end{tabular}

was $3925 \mathrm{~h}$, the wear rate of the gear with a pressure angle of $20^{\circ}$ was $2.57 \%$, while that of the gear with a pressure angle of $35^{\circ}$ was only $0.88 \%$. In the same testing time, the average wear of the gear with a pressure angle of $35^{\circ}$ was significantly lower than that for a gear with a pressure angle of $20^{\circ}$. This phenomenon indicated that the wear of the modified gear with a pressure angle of $35^{\circ}$ was less than that of the basic gear with a pressure angle of $20^{\circ}$.

The analysis of the abovementioned results indicated that the modified gear with a pressure angle of $35^{\circ}$ was

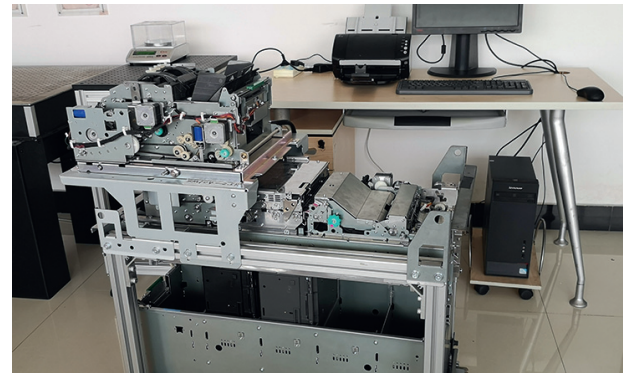

FIGURE 11: TCRMe1000 large circulation module testing machine. 


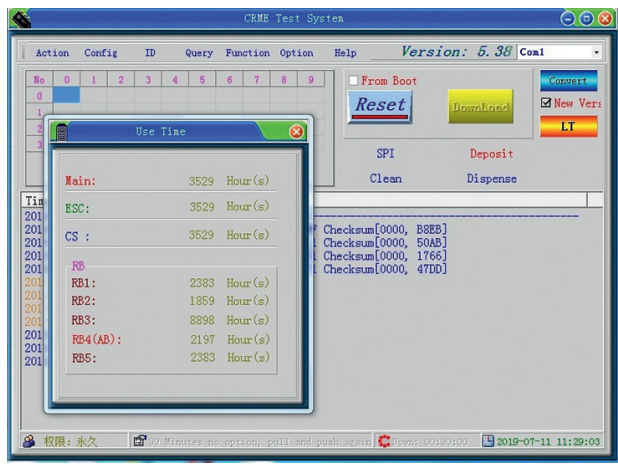

FIGURE 12: Result of wear test for 3529 hours.
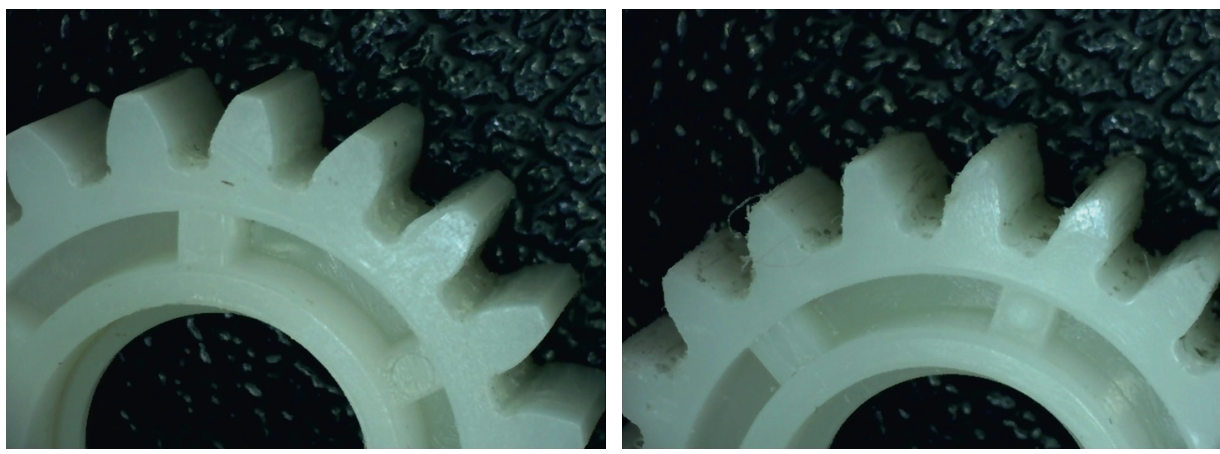

FIGURE 13: Photographs of the tooth profile of the gear with a pressure angle of $20^{\circ}$ before (a) and after (b) the wear test.
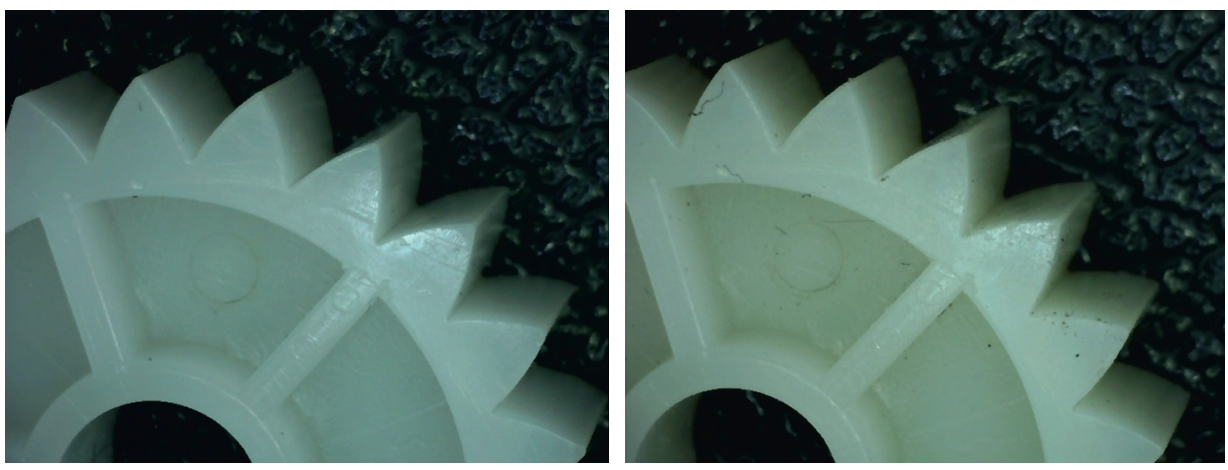

FIGURE 14: Photographs of the tooth profile of the gear with a pressure angle of $35^{\circ}$ before (a) and after (b) the wear test.

TABLE 4: Effect of testing time on gear wear rate and single tooth wear quality.

\begin{tabular}{lcccc}
\hline \multirow{2}{*}{$\begin{array}{c}\text { Working } \\
\text { hours (h) }\end{array}$} & $\begin{array}{c}\text { Gear with a pressure } \\
\text { angle of } 20^{\circ}\end{array}$ & $\begin{array}{c}\text { Gear with a pressure } \\
\text { angle of } 35^{\circ}\end{array}$ & $\begin{array}{c}\text { Wear quality of single tooth (mg) } \\
\text { Gear with a pressure }\end{array}$ & $\begin{array}{c}\text { Gear with a pressure } \\
\text { angle of } 35^{\circ}\end{array}$ \\
\hline 1000 & $0.08 \pm 0.01$ & $0.06 \pm 0.01$ & $0.06 \pm 0.01$ & $0.07 \pm 0.01$ \\
2000 & $0.23 \pm 0.01$ & $0.19 \pm 0.01$ & $0.28 \pm 0.01$ & $0.21 \pm 0.01$ \\
3000 & $1.03 \pm 0.01$ & $0.52 \pm 0.01$ & $0.86 \pm 0.01$ & $0.58 \pm 0.01$ \\
3925 & $2.57 \pm 0.01$ & $0.88 \pm 0.01$ & $2.13 \pm 0.01$ & $1.01 \pm 0.01$ \\
\hline
\end{tabular}

better than the basic gear with a pressure angle of $20^{\circ}$ in terms of the contact stress, relative sliding speed, and friction heat flux, and the data obtained in practical experiments were consistent with the theoretical analysis results.

\section{Conclusion}

This study investigated and analyzed the gear transmission mechanism considering the special requirements of the gear transmission mechanism for the cash circulation module of 
financial machinery, such as compact structure, high transmission accuracy, large torque, fast speed, high temperature, no lubrication, and long service life. A plastic gear with a pressure angle of $35^{\circ}$ was designed. Through kinematic analysis and experimental verification, the designed gear was noted to satisfy the performance requirements of financial machinery and achieved the set targets. The research results indicated that with an increase in the pressure angle, the average contact pressure on the tooth surface of plastic gears decreased and the maximum reduction was up to $15.9 \%$, demonstrating a significant downward trend. The relative sliding velocity of the meshing tooth surface was related to the pressure angle of the gear. With an increase in the pressure angle, the relative sliding velocity decreased and the relative sliding wear between the teeth decreased. With an increase in the pressure angle, the friction heat flux of the gear teeth decreased at each point of the meshing area and the maximum value of friction heat flux decreased primarily at the small tooth root and the top of the large gear teeth. Therefore, increasing the pressure angle suitably was beneficial in reducing the friction heat generation on the tooth surface. An increase in the pressure angle of the gear could make the involute of the gear extend to the root circle and considerably reduce the wear caused by the interference of the plastic gear teeth. The practical application test demonstrated that the service life of the gear increased considerably with an increase in the pressure angle.

\section{Data Availability}

The data used to support the findings of this study are included within the article.

\section{Conflicts of Interest}

The authors declare no conflicts of interest.

\section{Acknowledgments}

This work was supported by the Hangzhou Major Science, Technology Innovation Project-Dongxin Remote Intelligent Banking System (VTM Finance), and Plan of Science and Technology Development of Jilin Province of China (no. 20180520204JH).

\section{References}

[1] X. Zhang and G. Liu, "Theoretical discussion and experimental research on plastic gear," Hydraulic and Electric Machinery, vol. 5, 1990.

[2] L. Qiu, X. Xin, T. Wang, and S. Jiang, "Calculation of temperature field and thermal deformation modification of gear body," Journal of Shang Hai Jiao Tong University, vol. 29, 1995.

[3] S. Lu and H. Meng, "Thermal analysis of plastic gear," Plastics, vol. 32, 2003.

[4] S. E. Franklin, "Wear experiments with selected engineering polymers and polymer composites under dry reciprocating sliding conditions," Wear, vol. 251, no. 1-12, pp. 1591-1598, 2001.

[5] S. S. Yousef, D. J. Burns, and W. McKinlay, "Techniques for assessing the running temperature and fatigue strength of thermoplastic gears," Mechanism and Machine Theory, vol. 8, no. 2, pp. 175-185, 1973.

[6] J. H. Chen, F. M. Juarbe, and M. A. Hanley, "Factors affecting fatigue strength of nylon gears," Journal of Mechanical Design, vol. 103, no. 2, pp. 543-548, 1981.

[7] S. E. Franklin and A. de Kraker, "Investigation of counterface surface topography effects on the wear and transfer behaviour of a POM-20\% PTFE composite," Wear, vol. 255, no. 1-6, pp. 766-773, 2003.

[8] B. Hu and C. Long, "Study on polyformaldehyde wear-resistant composite," Journal of Hunan University of Science and Technology: Natural Science Edition, vol. 19, no. 4, pp. 51-54, 2004.

[9] H. T. Wang, S. R. Yang, and Q. Q. Xue, "Tribological properties of polyformaldehyde/PTFE blends," Polymer Materials Science and Engineering, vol. 12, no. 2, pp. 115-118, 1996.

[10] D. B. Wallace and A. Seireg, "Computer simulation of dynamic stress, deformation, and fracture of gear teeth," Journal of Engineer for Industry, vol. 95, no. 4, p. 1108, 1973.

[11] Y. Wu, C. Y. Hua, and C. G. Long, "Tribological properties of polyformaldehyde-based composites under different loading and rotating speeds," Journal of Lubrication and Sealing, vol. 6, pp. 32-35, 2006.

[12] M. Taburdagitan and M. Akkok, "Determination of surface temperature rise with thermo-elastic analysis of spur gears," Wear, vol. 261, no. 5-6, pp. 656-665, 2006.

[13] K. Mao, "A numerical method for polymer composite gear flash temperature prediction," Wear, vol. 262, no. 11-12, pp. 1321-1329, 2007.

[14] A. Kapelevich, "Geometry and design of involute spur gears with asymmetric teeth," Mechanism and Machine Theory, vol. 35, no. 1, pp. 117-130, 2000.

[15] H. Long, A. A. Lord, D. T. Gethin, and B. J. Roylance, "Operating temperatures of oil lubricated medium speed gears: numerical models and experimental results," Proceedings of the Institution of Mechanical Engineers, Part G: Journal of Aerospace Engineering, vol. 217, no. 2, pp. 80-103, 2003.

[16] H. Sun, Z. Chen, and W. Ge, Principles of Mechanics, People's Education Press, Beijing, China, 8th edition, 2010.

[17] Y. Wang, Calculation Principle of Friction and Wear, Machinery Industry Press, Beijing, China, 1982.

[18] Y. Diab, F. Ville, and P. Velex, "Investigations on power losses in high-speed gears," Proceedings of the Institution of $\mathrm{Me}$ chanical Engineers, Part J: Journal of Engineering Tribology, vol. 220, no. 3, pp. 191-198, 2006.

[19] Z. Wang, "Sliding rate analysis of involute gear teeth," Journal of Lan Zhou Jiao Tong University, vol. 33, 2014. 